\title{
Effect of melittin on prostaglandin production by guinea-pig uterus
}

\author{
F. A. Johnson and N. L. Poyser* \\ Department of Pharmacology, University of Edinburgh Medical School, 1 George Square, \\ Edinburgh EH8 9JZ, UK
}

\begin{abstract}
Summary. Melittin, an activator of phospholipase (PL) A-2, increased the outputs of prostaglandin (PG) F-2 $\alpha$ and 6-keto-PGF-1 $\alpha$, but not of PGE-2, from Day-7 guineapig uterus superfused in vitro. Reducing the extracellular calcium concentration (by omitting calcium chloride from the superfusing fluid) partially inhibited the stimulatory effect of melittin on uterine PG production. TMB-8 (an intracellular calcium antagonist) completely prevented the stimulation of PGF-2 $\alpha$ and 6-keto-PGF-1 $\alpha$ output by melittin, although the production of both PGs tended to increase after stopping the melittin and TMB-8 treatments. TMB- 8 also inhibited the increases in outputs of PGF$2 \alpha, 6-k e t o-P G F-1 \alpha$ and PGE-2 and prevented contraction of the uterus induced by exogenous PLA-2. Trifluoperazine (a calmodulin antagonist) had no inhibitory effect on the increases in outputs of PGF- $2 \alpha$ and 6-keto-PGF- $1 \alpha$ produced by melittin; it potentiated the stimulatory effect of melittin on 6-keto-PGF-1 $\alpha$ output and allowed melittin to increase PGE-2 output. When melittin was applied twice to the superfused uterus with an interval of $1 \mathrm{~h}$ between each treatment, partial refractoriness of the responses to melittin was seen: the magnitudes of the increases in PGF-2 $\alpha$ and 6keto-PGF-1 $\alpha$ outputs were $40-50 \%$ less after the second treatment than after the first treatment. These results show that melittin stimulates the synthesis of PGF- $2 \alpha$ and PGI-2 (measured as 6-keto-PGF-1 $\alpha$ ) in guinea-pig uterus by mechanisms which are calcium dependent. The results are compatible with there being a protein of similar functional activity to melittin in the guinea-pig uterus, which may be involved in the stimulation of endometrial PGF- $2 \alpha$ synthesis.
\end{abstract}

Keywords: melittin; TMB-8; trifluoperazine; prostaglandins; guinea-pig; uterus

\section{Introduction}

Endometrial prostaglandin (PG) F-2 $\alpha$ synthesis in guinea-pigs is dependent upon increased protein synthesis (Poyser, 1979; Poyser \& Riley, 1987; Riley \& Poyser, 1989). The findings from these and other studies indicate that oestradiol, acting on a progesterone-primed uterus, stimulates the synthesis of a protein which activates phospholipase (PL) A-2, by either mobilizing calcium or interacting synergistically with calcium. The activated PLA-2 releases arachidonic acid from phospholipids for PGF-2 $\alpha$ synthesis (see Riley \& Poyser, 1989). A PLA-2-stimulating protein (PLAP), which is antigenically and functionally related to the PLA-2-stimulating peptide melittin, has been isolated from various cultured cell lines; this protein is an 'intracellular messenger' in the stimulation of PG synthesis (Clark et al., 1987, 1988). Consequently, the effect of melittin on PG production by guinea-pig uterus has been investigated to see whether a functionally similar PLA-2stimulating protein is active in guinea-pig uterus.

*Reprint requests. 


\section{Materials and Methods}

Procedures. Thirty virgin guinea-pigs (5 animals per experiment) weighing $600-900 \mathrm{~g}$ were examined daily and a vaginal smear was taken when the vagina was perforate. Day 1 of the cycle was taken as the day preceding the postovulatory influx of leucocytes when cornification was at a maximum. All guinea-pigs had exhibited at least 2 consecutive cycles of normal length before being used on Day 7 of the cycle. Each uterus was removed and separated into its 2 horns. The uterine horns were weighed, 'opened' by cutting longitudinally and superfused with Krebs' solution $\left(5 \mathrm{ml} / \mathrm{min}\right.$ ) at $37^{\circ} \mathrm{C}$ as described by Poyser \& Brydon (1983). In Expts 1-5, each uterine horn was superfused initially for a 'settling period' of $60 \mathrm{~min}$. Samples of superfusate were then collected for 10-min periods over the next $80 \mathrm{~min}$ (i.e. 8 samples/uterine horn; Expts 1 and 2) or $100 \mathrm{~min}$ (i.e. 10 samples/uterine horn; Expts 3-5). In Expt 6, only one uterine horn from each animal was used and, after an initial settling period of $40 \mathrm{~min}, 16$ samples of superfusate were collected for $10-\mathrm{min}$ periods over the next $160 \mathrm{~min}$. The uterine horns in each experiment were treated as described below.

Treatments. In Expt 1, melittin $(2 \mu \mathrm{g} / \mathrm{ml})$ was present in the Krebs' solution superfusing one uterine horn from each animal during the collection of samples 4 and 5 . The other uterine horn from each animal was untreated. In Expt 2, one uterine horn from each animal was superfused with normal Krebs' solution and the other uterine horn was superfused with Krebs' solution from which the calcium chloride had been omitted (i.e. calcium-depleted Krebs' solution). Melittin $(2 \mu \mathrm{g} / \mathrm{ml})$ was present in both types of Krebs' solution during the collection of samples 4 and 5 . In Expts 3 and 4, both uterine horns from each animal were superfused with normal Krebs' solution, and melittin $(2 \mu \mathrm{g} / \mathrm{ml})$ was present in the solution superfusing both uterine horns during the collection of samples 4 and 5 . In addition, $150 \mu \mathrm{M}-8$-( $N, N$-diethylamino)octyl-3,4,5,-trimethoxybenzoate hydrochloride (TMB-8; an intracellular

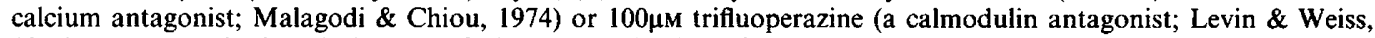
1977) was present in the solution superfusing one uterine horn from each animal during the collection of samples 4-7. In Expt 5, PLA-2 (2 U/ml) was present in the Krebs' solution superfusing both uterine horns from each animal during

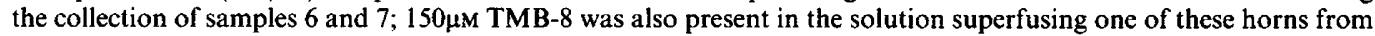
each animal during the collection of samples 4-7. In Expt 6, melittin $(2 \mu \mathrm{g} / \mathrm{ml})$ was present in the Krebs' solution superfusing the uterine horns during the collection of samples $4,5,12$ and 13.

Assays. After collection, the $\mathrm{pH}$ of each sample was lowered to 4.0 with $\mathrm{HCl}$ and the PGs were extracted by shaking twice with $50 \mathrm{ml}$ ethyl acetate. The two ethyl acetate fractions were combined and evaporated to dryness at $50^{\circ} \mathrm{C}$ on a rotary evaporator. The recoveries of PGF- $2 \alpha$ and PGE-2 are $>90 \%$ and the recovery of 6-keto-PGF-l $\alpha$ is $>80 \%$ by this method (Poyser \& Scott, 1980; Swan \& Poyser, 1983). The results were not corrected for recovery. Each dried extract was redissolved in $10 \mathrm{ml}$ ethyl acetate and stored at $-20^{\circ} \mathrm{C}$. The amounts of PGF-2 $\alpha$, PGE- 2 and 6-ketoPGF-l $\alpha$ present in each sample were measured by radioimmunoassay using antibodies raised in this laboratory and whose cross-reactivities have been reported elsewhere (Poyser, 1987). The inter- and intra-assays coefficients of variation were $<12 \%$. The detection limit was $20-30 \mathrm{pg}$ PG/assay tube.

Sources of material. Melittin, TMB-8, trifluoperazine and PLA-2 (EC 3.1.1.4, from Naja naja venom) were purchased from Sigma Chemical Co., Poole, Dorset, UK.

Statistical tests. Changes in the outputs of the PGs with time were analysed by Duncan's multiple range test. Other comparisons were made using Student's $t$ test or the paired $t$ test, as appropriate.

\section{Results}

Melittin significantly $(P<0.05)$ increased the outputs of PGF-2 $\alpha$ and 6-keto-PGF-1 $\alpha$, but not PGE-2, from the Day-7 superfused uterus (Fig. 1a). The omission of calcium from the Krebs' solution significantly $(P<0.05)$ reduced, but did not completely inhibit this stimulation of PGF-2 $\alpha$ production by melittin (Fig. 1b). The increase in output of 6-keto-PGF-1 $\alpha$ output produced by melittin also tended to be reduced by the omission of calcium, but the differences were not statistically significant (Fig. Ib). TMB-8 increased the basal output of PGE-2 without affecting the basal outputs of PGF-2 $\alpha$ and 6-keto-PGF-1 $\alpha$ (Fig. 2a). Also, TMB-8 significantly $(P<0.05)$ prevented the increases in outputs of PGF- $2 \alpha$ and 6-keto-PGF-1 $\alpha$ produced by melittin. After finishing treatment, the ouputs of PGF-2 $\alpha$ and 6-keto-PGF-1 $\alpha$ from the uterine horn treated with TMB-8 and melittin increased significantly $(P<0.05)$ to approach those values observed after finishing treatment of the uterine horn with melittin alone (Fig. 2a). Trifluoperazine tended to increase the basal outputs of PGF-2 $\alpha$, PGE-2 and 6-keto-PGF-1 $\alpha$, but the increases were not statistically significant (Fig. 2b). Trifluoperazine had no inhibitory effect on the increases in PGF-2 $\alpha$ and 


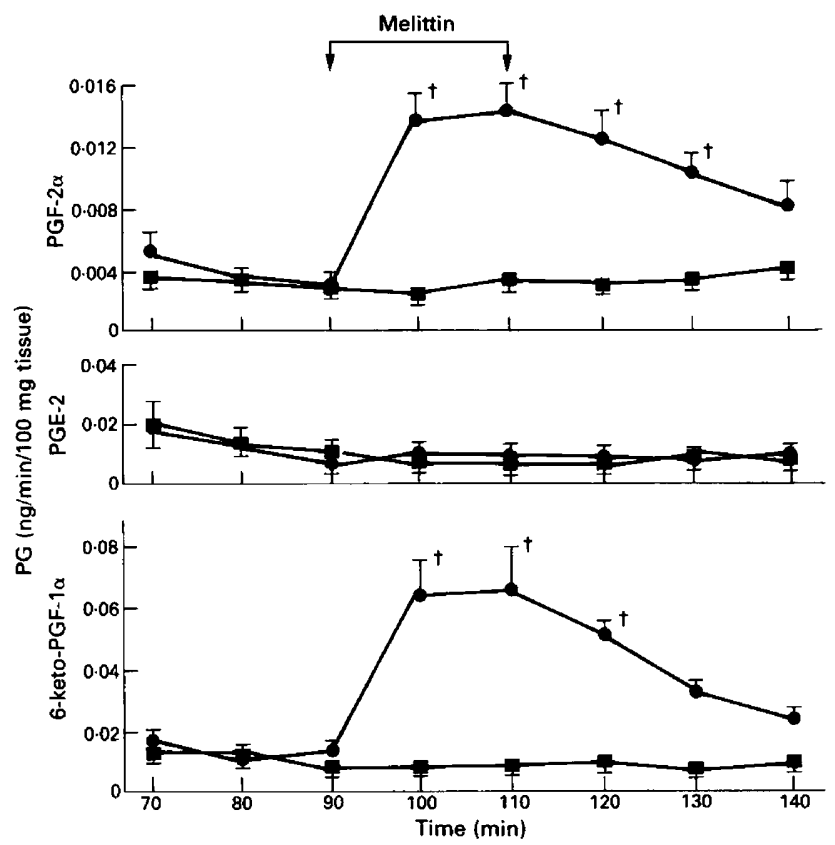

Fig. 1. (a).

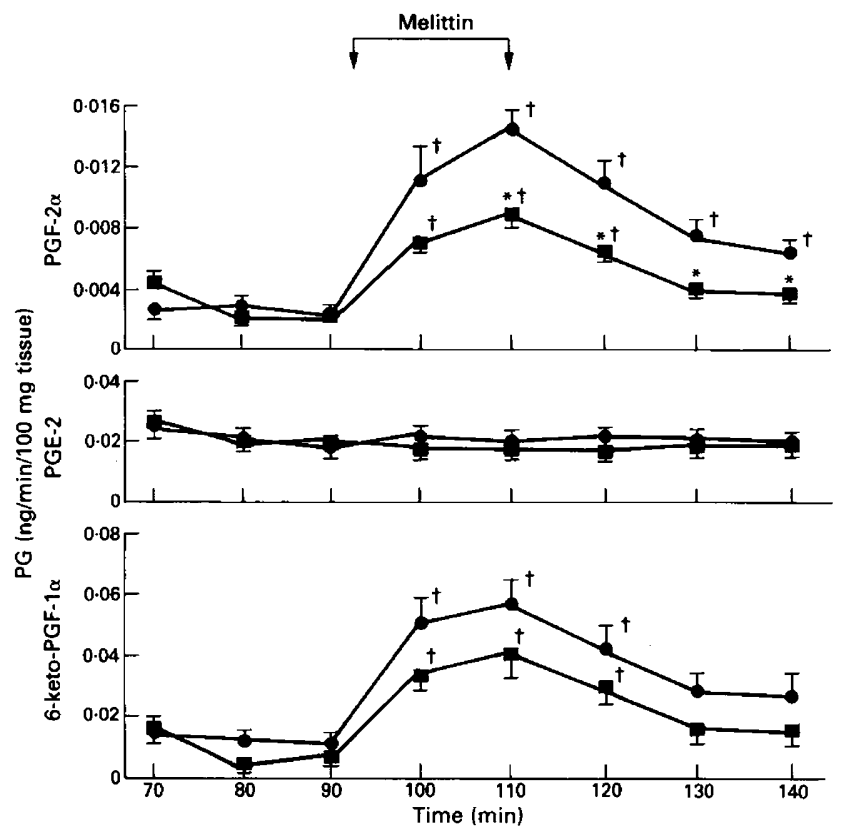

Fig. 1. (b).

Fig. 1. Effect of melittin $(2 \mu \mathrm{g} / \mathrm{ml})$ on mean ( \pm s.e.m., $n=5)$ outputs of prostaglandin (PG) F-2 $\alpha$, PGE-2 and 6-keto-PGF-1 $\alpha$ from Day-7 guinea-pig superfused uterus using (a) normal Krebs' solution ( $\square$ control, treated) and (b) normal Krebs' solution ( $O$ with calcium) and calcium-depleted Krebs' solution ( $\square$ without calcium). †Significantly $(P<0.05)$ higher than before melittin treatment. "Significantly $(P<0.05)$ lower than the corresponding value for Krebs solution with calcium. 


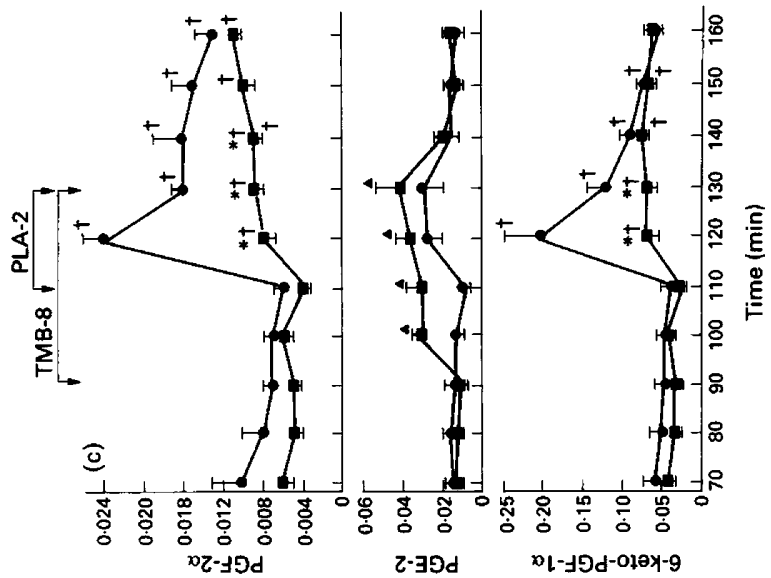

(әnss! $6 \mathrm{6u} 00 \mathrm{l} / \mathrm{u!u/6u}$ ) פd
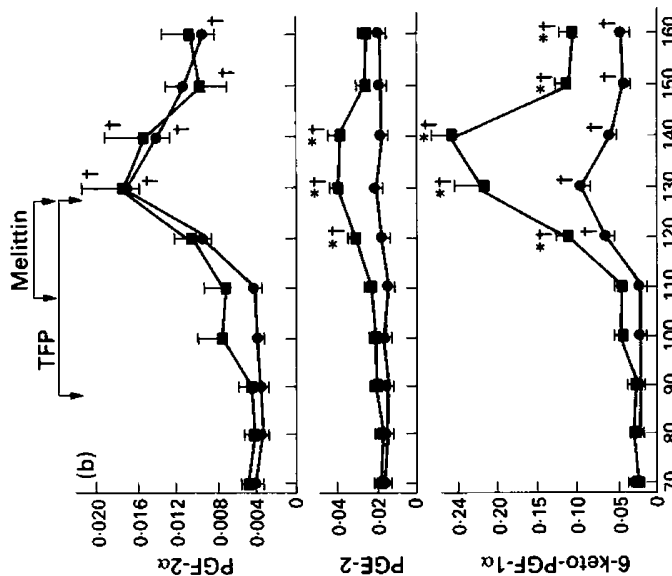

(ənss!! 6u 00l/u!u/6u) פd

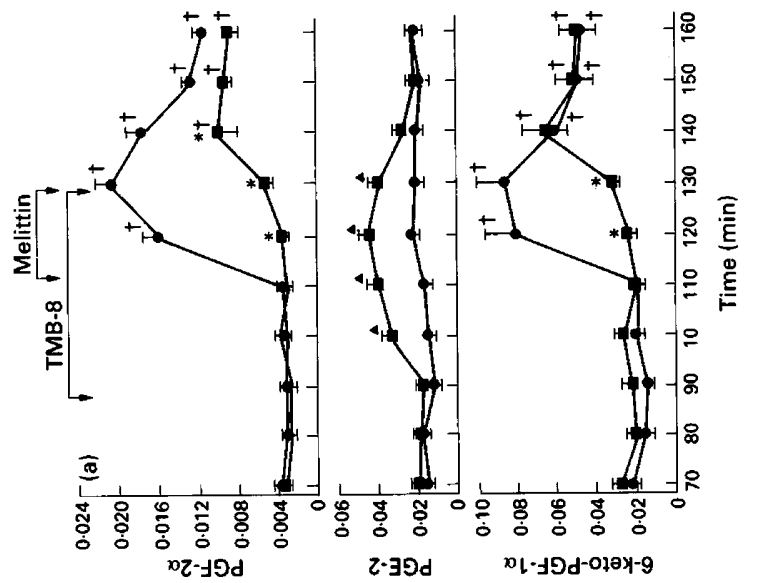

至额领 言焉结 을

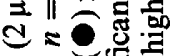
르릉ํㅇ क $\exists+1 \tilde{\omega}^{*} v$ 可高

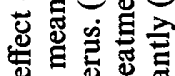
号 疍 ธี ธิษ

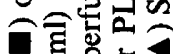

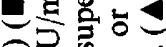
过.

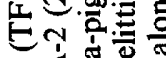
$0<\Phi$

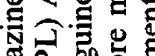

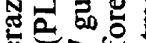

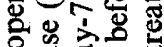
咩

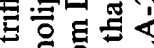

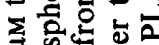

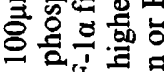
อิธण 记家家

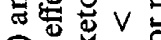
-

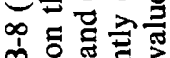

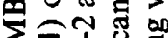
$\sum_{1}$ 政:

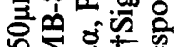
经过

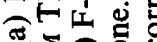

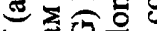
궁롱

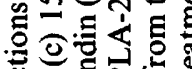

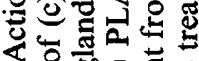
<然苟 ง.

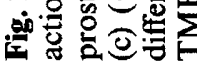

(ənss!! 6u 00L/u!u/6u) פd 


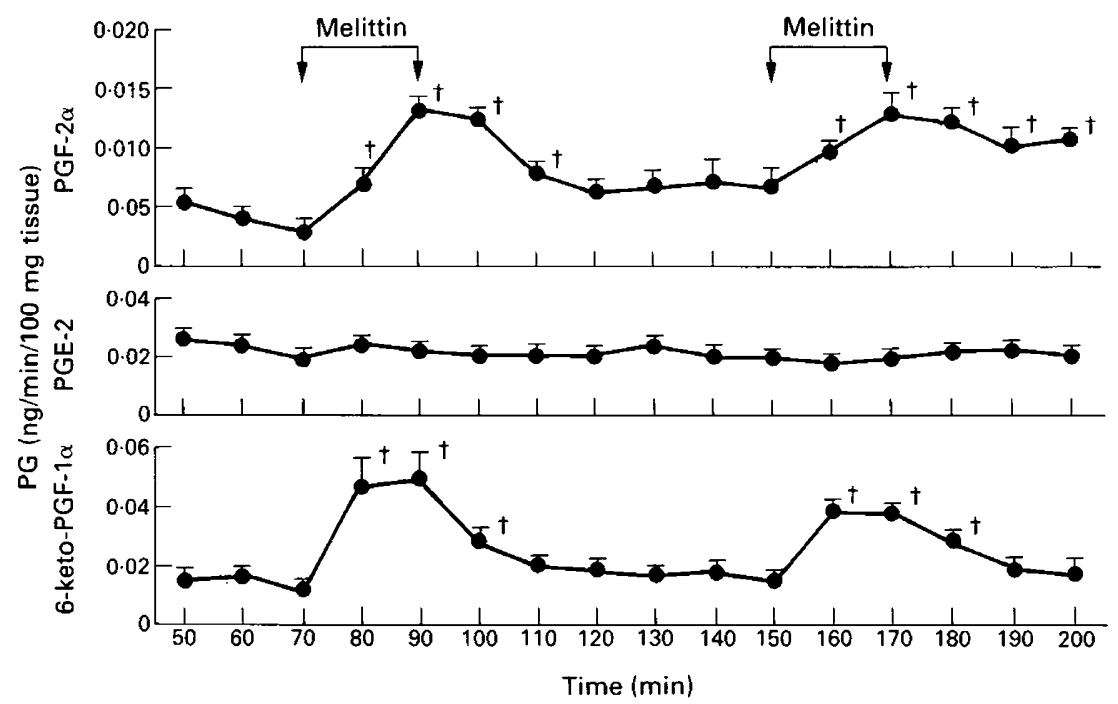

Fig. 3. Effect of melittin $(2 \mu \mathrm{g} / \mathrm{ml})$ on mean ( \pm s.e.m., $n=5)$ outputs of prostaglandin $(P G) F-$ $2 \alpha$, PGE-2 and 6-keto-PGF-1 $\alpha$ from Day-7 guinea-pig superfused uterus following repeated treatment at an interval of $1 \mathrm{~h}$. † Significantly $(P<0.05)$ higher than before melittin treatment.

6-keto-PGF-1 $\alpha$ outputs produced by melittin; it potentiated the stimulatory effect of melittin on 6-keto-PGF-1 $\alpha$ output and allowed melittin to increase significantly $(P<0.05)$ the output of PGE-2 (Fig. 2b). PLA-2 significantly $(P<0 \cdot 05)$ increased the outputs of PGF-2 $\alpha, 6$-keto-PGF-1 $\alpha$ and, to a lesser extent, PGE-2 (Fig. 2c). TMB-8 significantly $(P<0.05)$ inhibited the increases in outputs of PGF- $2 \alpha$ and 6-keto-PGF-1 $\alpha$ produced by PLA-2. Similarly, TMB-8 probably prevented the stimulatory effect of PLA-2 on PGE 2 output, although the effect of TMB- 8 was not clear, since it stimulated PGE-2 output on its own (Fig. 2c). PLA-2 caused each uterine horn to contract and to remain contracted. TMB-8 completely prevented this increase in uterine tone produced by PLA-2.

Melittin initially stimulated the outputs of PGF-2 $\alpha$ and 6-keto-PGF-1 $\alpha$ by 4.4 and 3.9 times, respectively (Fig. 3). When administered again $1 \mathrm{~h}$ after the first treatment had finished, melittin stimulated the outputs of PGF-2 $\alpha$ and 6-keto-PGF- $1 \alpha$ by $2 \cdot 3$-fold and $2 \cdot 4$-fold, respectively (Fig. 3). Hence, the magnitude of the responses to melittin were reduced during the second course of treatment. The output of PGE-2 was not affected by either treatment with melittin.

\section{Discussion}

From fluorometric measurements on the interaction of melittin with phosphatidylcholine (PC), it has been proposed that 'melittin forms a complex with one or several molecules of lecithin or similar phospholipid. While the phospholipids in the membrane are largely protected from the action of PLA-2, it is visualised that melittin can thus present substrate to enzyme' (Mollay \& Kreil, 1973). Further fluorescence studies indicated that the indole ring in the single tryptophan residue of melittin is transferred to an apolar environment after the interaction of melittin with Escherichia coli $(E$. coli) cytoplasmic membranes or phosphatidylethanolamine (PE) liposomes (Mollay et al., 1976). The activity of endogenous PLA-2 is low in E. coli membranes, but a 6-7-fold stimulation is obtained by the addition of melittin (Mollay et al., 1976). The activation of PLA-2 by sublytic concentrations of melittin ( $\geqslant 10 \mu \mathrm{g} / \mathrm{ml}$ ) in 3T3-4a mouse fibroblasts results in the release of arachidonic acid from phospholipids and the conversion of the arachidonic acid into PGs (Shier, 1979). 
Phospholipases B and C, sphingomyelinases and lipases are not stimulated by melittin (Shier, 1979).

In the present study on guinea-pig superfused uterus, melittin caused $\sim 4-5$-fold increases in the ouputs of PGF-2 $\alpha$ and 6-keto-PGF-1 $\alpha$, which are the major PGs synthesized by the endometrium and myometrium, respectively (Poyser, 1983), although the endometrium synthesizes and secretes 6-keto-PGF-1 $\alpha$ also (Riley \& Poyser, 1987). PGE-2 output from the uterus was little affected by melittin, although melittin does stimulate PGE-2 production by 3T3-4a mouse fibroblasts (Shier, 1979). The stimulation of uterine PG production by melittin was unlikely to be due to contamination with PLA-2, since the maximum amount of PLA-2 which could have been present was $<10 \mathrm{mU} / \mathrm{ml}$, and $2 \mathrm{U}$ PLA $-2 / \mathrm{ml}$ are required to produce a comparable stimulation of PG output (Poyser, 1987). Also, exogenous PLA-2 stimulated uterine PGE-2 output while melittin had no effect. The stimulation of uterine PGF-2 $\alpha$ and 6-keto-PGF-1 $\alpha$ outputs by melittin was fairly rapid, peak output usually being achieved in the first 10 -min period of treatment.

The increases in the outputs of PGF- $2 \alpha$ and, to a lesser extent, 6-keto-PGF-1 $\alpha$ were reduced, but not totally inhibited, by considerably reducing the extracellular calcium concentration. TMB- 8 (an intracellular calcium antagonist) completely prevented the stimulation of PGF-2 $\alpha$ and 6-ketoPGF-1 $\alpha$ outputs by melittin. These results indicate that the action of melittin is dependent upon the presence of calcium. This is in agreement with the study of Shier (1979), who found that the stimulation of PLA-2 by melittin in 3T3-4a mouse fibroblasts was also dependent upon calcium, since the addition of EDTA to the culture medium prevented the increase in PG production produced by melittin. TMB-8 also inhibited the increases in PG output from guinea-pig superfused uterus produced by PLA-2, suggesting that the action of exogenous PLA-2 is also dependent upon the presence and/or mobilization of intracellular calcium. This suggestion is supported by the finding that TMB-8 inhibited contraction of the uterus produced by PLA-2. Alternatively, TMB-8 may inhibit the action of PLA-2 directly, which may mean that TMB-8 inhibits the action of endogenous PLA-2 directly. However, TMB-8 had no inhibitory effect on basal PG output (suggesting it was not inhibiting endogenous PLA-2 directly) and, in fact, stimulated uterine PGE-2 output as reported previously (Poyser, 1985a).

Trifluoperazine (a calmodulin antagonist) had no inhibitory effect on the stimulation of PGF$2 \alpha$ and 6-keto-PGF-l $\alpha$ outputs by melittin, indicating that calmodulin is not involved in the intracellular processes by which melittin stimulates the synthesis of PGF-2 $\alpha$ and PGI-2 (as reflected by $6-k$ to-PGF-1 $\alpha$ ). In fact, trifluoperazine potentiated the increase in 6-keto-PGF-1 $\alpha$ output produced by melittin, and allowed melittin to stimulate uterine PGE-2 production. This potentiating action may be due to trifluoperazine releasing membrane-bound, intracellular calcium (see Poyser, 1985b).

In a previous study, it was shown that guinea-pig uterus is completely refractory to the stimulant action of exogenous PLA-2 on PG output when a second treatment is started $1 \mathrm{~h}$ after the first treatment with PLA-2 has finished (Poyser, 1991). Partial refractoriness is observed when the uterus is similarly treated with A23187. In the present study, partial refractoriness to the stimulant action of melittin was observed, since the magnitude of the increases in PGF-2 $\alpha$ and 6-keto-PGF$1 \alpha$ outputs were reduced by $40-50 \%$ when melittin was applied for the second time $1 \mathrm{~h}$ after the first treatment had finished.

In conclusion, this study has shown that melittin (an activator of endogenous PLA-2) acts on guinea-pig uterus by a calcium-dependent process to stimulate the production of PGF- $2 \alpha$ (the major PG produced by the endometrium). The production of 6-keto-PGF-1 $\alpha$, but not of PGE-2, is also stimulated by melittin. The results are compatible with the suggestion that there could be a protein functionally similar to melittin in the guinea-pig uterus which is involved in the stimulation of endometrial PGF- $2 \alpha$ synthesis at the end of the oestrous cycle.

This study was supported by a grant from the MRC. The technical assistance of L. Turnbull is greatly appreciated. 


\section{References}

Clark, M.A., Conway, T.M., Shorr, R.G.L. \& Crooke, S.T. (1987) Identification and isolation of a mammalian protein which is antigenically and functionally related to the phospholipase $A_{2}$ stimulating peptide melittin. J. biol. Chem. 262, 4402-4407.

Clark, M.A., Chen, M.-J., Crooke, S.T. \& Bornalalaski, J.S. (1988) Tumour necrosis factor (cachetin) induces phospholipase $A_{2}$ activity and synthesis of a phospholipase $A_{2}$-activating protein in endothelial cells. Biochem. J. 250, 125-132.

Levin, R.M. \& Weiss, B. (1977) Binding of trifluoperazine to the calcium dependent activator of cyclic nucleotide phosphodiesterase. Molec. Pharmac. 13, 690-697.

Malagodi, M.H. \& Chiou, C.Y. (1974) Pharmacological evaluation of a new $\mathrm{Ca}^{2+}$ antagonist, $8-(N, N$. diethylamino)-octyl-3,4,5,-trimethoxybenzoate hydrochloride (TMB-8): studies in smooth muscle. Eur. J. Pharmac. 27, 25-33.

Mollay, C. \& Kreil, G. (1973) Fluorometric measurements on the interaction of melittin with lecithin. Biochem. Biophys. Acta 316, 196-203.

Mollay, C., Kreil, G. \& Berger, H. (1976) Action of phospholipases on the cycloplasmic membrane of Escherichia coli. Stimulation by melittin. Biochem. Biophys. Acta 426, 317-324.

Poyser, N.L. (1979) Effect of actinomycin D on uterine prostaglandin production and oestrous cycle length in guinea-pigs. J. Reprod. Fert. 56, 559-565.

Poyser, N.L. (1983) Differential stimulation of prostaglandin and thromboxane synthesizing capacities in the guinea-pig uterus and ovary. Prostaglandins, Leuk. \& Med. 10, 162-177.

Poyser, N.L. (1985a) Effects of TMB-8, and intracellular calcium antagonist, and W-7, a calmodulin antagonist, on prostaglandin output from the guinea-pig uterus. J. Reprod. Fert. 75, 223-230.
Poyser, N.L. (1985b) Effect of trifluoperazine, a calmodulin antagonist, on prostaglandin output from the guinea-pig uterus. J. Reprod. Fert. 73, 295-303.

Poyser, N.L. (1987) Effects of various factors on prostaglandin synthesis by the guinea-pig uterus. J. Reprod. Fert. 81, 269-276.

Poyser, N.L. (1991) A possible explanation for the refractoriness of uterine prostaglandin production. $J$. Reprod. Fert. 91, 371-384.

Poyser, N.L. \& Brydon, L.J. (1983) Prostaglandin release from the guinea-pig uterus superfused in vitro. Effect of stage of estrous cycle, progesterone, estradiol, oxytocin and A23187. Prostaglandins 25, 443-456.

Poyser, N.L. \& Riley, S.C. (1987) Effect of actinomycin $\mathrm{D}$ on prostaglandin synthesis by and output from the guinea-pig uterus. Prostaglandins, Leuk. \& Med. 28, 153-168.

Poyser, N.L. \& Scott, F.M. (1980) Prostaglandin and thromboxane production by the rat uterus and ovary during the oestrous cycle. J. Reprod. Fert. 60, 33-40.

Riley, S.C. \& Poyser, N.L. (1987) Prostaglandin production by the guinea-pig endometrium: is calcium necessary? $J$. Endocr. 113, 463-471.

Riley, S.C. \& Poyser, N.L. (1989) Is protein synthesis necessary for prostaglandin production by guinea-pig endometrium? J. Reprod. Fert. 86, 73-89.

Shier, W.T. (1979) Activation of high levels of endogenous PLA $\mathrm{A}_{2}$ in cultivated cells. Proc. Natl Acad. Sci. USA 76, 195-199.

Swan, G.C. \& Poyser, N.L. (1983) Prostaglandin synthesis by, and the effects of prostaglandins and prostaglandin analogues on, the vas deferens of the rabbit and rat in vitro. J. Reprod. Fert. 69, 91-99.

Received 4 February 1991 